This is the author's final, peer-reviewed manuscript as accepted for publication. The publisher-formatted version may be available through the publisher's web site or your institution's library.

\title{
A study of engineering students' intercultural competence and its implications for teaching
}

Han Yu

\section{How to cite this manuscript}

If you make reference to this version of the manuscript, use the following information:

Yu, H. (2012). A study of engineering students' intercultural competence and its implications for teaching. Retrieved from http://krex.ksu.edu

\section{Published Version Information}

Citation: Yu, H. (2012). A study of engineering students' intercultural competence and its implications for teaching. IEEE Transactions on Professional Communication, 55(2), 185-201.

Copyright: (C) 2012 IEEE

Digital Object Identifier (DOI): doi:10.1109/TPC.2012.2186657

Publisher's Link:

http://ieeexplore.ieee.org/xpl/articleDetails.jsp?reload=true\&arnumber=6168237

This item was retrieved from the K-State Research Exchange (K-REx), the institutional repository of Kansas State University. K-REx is available at http://krex.ksu.edu 


\title{
A Study of Engineering Students' Intercultural Competence and Its Implications for Teaching
}

\author{
Han Yu \\ English Department \\ 108 E/CS Building \\ Kansas State University \\ Manhattan, KS 66506-6501 \\ hyu1@ksu.edu; 785-532-3339
}

\begin{abstract}
Research problem: The purpose of this study is to examine U.S. engineering students' intercultural competence and its pedagogical implications. Three research questions are addressed:
\end{abstract}

- What are engineering students' levels of awareness and sensitivity toward intercultural communication?

- What are their perceived needs in learning intercultural communication?

- Given these findings, what are some useful approaches and methods to teach intercultural communication in the engineering communication service class?

Literature review: The literature review examines current studies on U.S. engineering students' intercultural competence and establishes the scope of the study: intercultural awareness and sensitivity. The researcher consulted literature in intercultural studies, international education, and engineering education.

Methodology: The researcher conducted a mixed method study, using surveys, textual analysis, and interviews. 272 engineering undergraduates at a Midwestern public university participated in the study. Participants were recruited from an engineering communication class. Data were collected through survey instruments, written responses to cross-cultural dialogs and critical incidents, and interviews. Both qualitative and quantitative analyses were performed.

Results and Discussion: Participants exhibited vague and passive awareness of intercultural communication, average to high intercultural sensitivity (subject to self-assessment and social desirability bias), and partial acceptance of intercultural communication education. Based on 
these findings, the researcher suggests a cultural-general approach to teaching intercultural competence in engineering communication service classes. The study is limited to research participants at one institution and two aspects of intercultural competence. Future studies can involve diverse research participants, address more aspects of intercultural competence, and examine the use of cultural-general teaching methods in the classroom.

\section{Index Terms: Engineering, Intercultural, Competence}

Bio: Han Yu is an Assistant Professor at English Department, Kansas State University. Han's research focuses on technical writing assessment, intercultural technical communication, and visual communication. Her work has appeared in Technical Communication, Technical Communication Quarterly, Journal of Technical Writing and Communication, and Business Communication Quarterly. Email contact: hyu1@ksu.edu. 


\section{INTRODUCTION}

In the last decade or so, the U.S. engineering industry has, more than ever, sensed the impact of globalization. The international operation of industries, global research ventures, and multinational investments created a global technical environment [1, p.11]. At Siemens, for instance, "customers increasingly require solutions that integrate numerous complex technologies on a global basis"; a medical imaging user interface project alone involved "R\&D centers in Germany, the U.S., China, India, and Russia, and 45,000 people collaborating in a network of innovation around the world" [2, p. 4]. This global technical environment generated "a growing demand for a new type of engineer, one who breaks down cultural barriers and has the capability to effectively communicate and interface with professionals from other cultures" [3, p. 812].

Responding to this demand, U.S. engineering programs started to emphasize "soft" cultural skills, in addition to their traditional focus on "hard" technical skills [4]. Important initiatives were made in the engineering curriculum, including the requirements that students take foreign language and area study courses and participate in study/work abroad programs [1]. However, the topic of intercultural communication, especially intercultural communication in technical and professional contexts, was not adequately addressed in the engineering curriculum [5].

Teachers of technical communication can and should address this gap. At many institutions, engineering students are required to take at least one technical communication course, the socalled service class. This means technical communication teachers can reach a large number of engineering students if they address intercultural issues in this class. Furthermore, the goal of this class is to teach students effective communication in engineering; now that the engineering industry has globalized, the class should likewise be re-situated in that global context. Last, the field of technical communication has developed substantive pedagogical literature on intercultural communication, which can help teachers address this topic with engineering students [6-9].

Certainly, it is easy to say that technical communication teachers should contribute to engineering students' global education but it is much harder to determine how to do that. As $\mathrm{Yu}$ wrote, the topic of teaching intercultural issues in technical communication service classes receives insufficient discussion and faces many challenges: suitable textbooks and teaching materials are hard to come by, and time and curricular space tend to be limited [5]. In order to cover other important learning objectives, "culture" may be glossed over in these classes (if mentioned at all), which "may lead students to believe that culture is something of less importance or easy to grasp in one or two sections" [5, pp. 84-85]. And oftentimes, the teaching 
of culture may be reduced to imparting students with running lists of generalized and contextless cultural factoids.

This study proposes that to effectively teach intercultural communication in the service class, we

first need to understand engineering students' competence levels and learning needs. Specifically, the study explores the following questions: what are engineering students' levels of awareness and sensitivity toward intercultural communication? What are their perceived needs in learning intercultural communication? What are some useful approaches and methods to teach intercultural communication in the engineering communication service class?

In what follows, I report on this study. I first review studies that examine U.S. engineering students' intercultural competence and establish the scope of this study. I then describe the research methods used. Findings are reported and analyzed. Last, I describe the study's pedagogical implications, its limitations, and the need for future research.

\section{LITERATURE REVIEW}

Works in intercultural studies, international education, and engineering education were reviewed to help design and situate the present study. The sub-section Engineering Students' Intercultural Competence discusses completed and ongoing studies on engineering students' intercultural competence and informs the design of the present study. The sub-section Intercultural Awareness and Sensitivity establishes the two aspects of intercultural competence examined in this study: cognitive awareness and affective sensitivity.

\section{Engineering Students’ Intercultural Competence}

Current studies that assess U.S. engineering students' intercultural competence are generally conducted by engineering scholars, not technical communication scholars. As a result, these studies do not have a particular emphasis on intercultural communication. The number of existing studies is not high, and some are still ongoing [10-11]. As Thompson and Jesiek wrote, although engineering programs across the country have implemented initiatives to develop students' intercultural competence, there is no sufficient understanding on what intercultural abilities to assess or how to assess them [12]. Similarly, as Shen, Jesiek, and Chang wrote, relatively little is known about engineering students' intercultural competence prior to participating in these initiatives [13].

Among completed studies, Thompson and Jesiek assessed the intercultural sensitivity of a group of sophomore engineering students. Using the Intercultural Development Inventory, they found that $56.3 \%$ of the male participants scored in the Denial and Defense range [12]. In this range, 
one tends to deny the existence of cultural differences and see other cultures as suspicious or inferior [14]. Next, 41.2\% male participants scored at the level of Minimization [12]. At this level, one tends to minimize the truly important aspects of cultural differences, overgeneralize similarities, and recognize only the superficial and "harmless" differences [14]. Last, 2.5\% male participants scored in the Acceptance and Adaption range [12]. In this range, one would recognize and respect deeper levels of cultural differences and be able to adapt to those differences [14]. Among female participants, 31.3\% scored in the Denial and Defense range, 67.2\% were placed at the Minimization level, and 1.5\% scored in the Acceptance and Adaption range [12].

Other completed studies focus on providing comparative data. Rather than drawing tentative conclusions on particular engineering students' intercultural competence, they compare the performance of different groups of engineering students. Bielefeldt and High, using the MivilleGuzman Universality-Diversity Scale, compared the scores of students across two schools, genders, and years in school but did not give details of each group’s performance [15].

Still other studies focus on program assessment rather than student assessment. Comparing students who participate in a given intercultural education initiative and those who do not, these studies attempt to evaluate the effect of the education initiative in question. Shen et al., for instance, compared the intercultural competence of four groups of engineering students: those who were about to participate in three different types of global engineering programs and a baseline population of first-year engineering students [13]. They found that students who opt to participate in global programs tend to demonstrate more advanced cultural outlooks and discussed the programmatic implications of their findings [13]. Lohmann et al. compared the intercultural competence of Georgia Tech students (including a substantial portion of engineering students) who participated in the university's international plan initiative and those who did not and found, tentatively, that the former, especially in male-male comparison, had higher levels of intercultural competence [16].

The present study joins existing ones to address the literature gap on engineering students' intercultural competence. With its emphasis of intercultural communication and its focus on students' competence levels rather than program assessment, the present study can provide meaningful addition to existing literature.

Existing studies used or proposed various methods to assess engineering students' intercultural competence: standardized survey instruments such as the Pittsburg Freshman Engineering 
Attitudes Survey [15], the Miville-Guzman Universality-Diversity Scale [13, 15], and the Intercultural Development Inventory [12, 16]; surveys or questionnaires developed in house for particular programs [16]; interviews and focus groups [10, 16]; and scenario-based writing exercises [17]. Reflecting the literature, the present study, as described later, uses a number of methods including standardized and self-developed survey instruments, written responses, and interviews.

\section{Intercultural Awareness and Sensitivity}

As discussed earlier, engineering scholars are still in the process of developing frameworks to assess students' intercultural competence. Individual scholars and programs use different tools and focus on different aspects of intercultural competence. This is not surprising: how to define intercultural competence is always a point of contention among intercultural scholars. Various frameworks have been proposed to conceptualize this competence: awareness, knowledge, and skills [18]; mindset, heartset, and skillset [19]; sensitivity, awareness, and adroitness [20]; or awareness/ knowledge/information, attitudes, and skills [21]. Some of these conceptions overlap. Sensitivity and attitudes, for instance, both refer to one's feelings and emotions about cultural differences. Other terms conflict. Appreciation of cultural differences, for Tomlinson-Clarke, constitutes awareness [18], but for Chen and Starosta, it constitutes sensitivity [20].

To avoid these potential conceptual confusions when examining engineering students' intercultural competence, this study draws upon Chen and Starosta to conceive intercultural competence in terms of sensitivity, awareness, and skills (I chose "skills" in place of Chen and Starosta's original wording “adroitness”). In this framework, sensitivity is the affective ability and refers to one's desire to understand, appreciate, and accept cultural differences [22]; awareness is the cognitive ability and is concerned with "the understanding of culture conventions that affect how we think and behave” [20]; and skills is the behavioral ability and reflects one’s performance in intercultural interactions such as behavioral flexibility and interactional management [23, p. 49].

These three aspects are interrelated and often co-develop, but awareness and sensitivity are generally seen as the foundation of intercultural competence [24]. This is because understanding one's own as well as other people's cultures (awareness) can encourage students to develop positive emotions toward cultural differences (sensitivity); at the same time, this positive emotion will enhance and buffer the process of achieving awareness [20, 22, 23]. Only when students possess both awareness and sensitivity can they exhibit effective and appropriate behaviors in intercultural interactions. Following this framework and constrained by limited 
resources, this study focused on examining engineering students' cognitive awareness and affective sensitivity.

\section{METHODOLOGY}

This study intended to explore what are engineering students' levels of awareness and sensitivity toward intercultural communication, what are their perceived needs in learning intercultural communication, and given these findings, what are some useful approaches and methods to teach intercultural communication in the engineering communication service class. This section starts with an overview of the Choice of Research Methodology and Research Site and Participants, followed by the description of each research method and instrument: Awareness Survey, Sensitivity Survey, Student Written Responses, and Student Interviews. Last, Qualitative Data Analysis explains the software used for qualitative analysis.

\section{Choice of Research Methodology}

The researcher sees intercultural competence as a complex variable that can be measured quantitatively yet requires contextual details to qualify those measurements. A mixed methods research design was therefore chosen to allow both qualitative and quantitative interpretations. The study triangulated research and data collection methods to enhance validity and reliability. Between-method triangulation involves the use of multiple research methods (surveys, textual analysis, and interviews); within-method triangulation includes the use of multiple instruments (two sensitivity survey instruments).

\section{Research Site and Participants}

This study was conducted at a large Midwestern public university in the United States, and it was approved by the university’s Institutional Review Board (IRB). Participants were recruited from multiple sections of an engineering communication class required of all engineering undergraduates at the university. Participants were predominantly white males in their early 20s. They included third-, fourth-, and fifth-year students who majored in mechanical engineering, chemical engineering, biological and agricultural engineering, civil engineering, architectural engineering, electrical engineering, industrial engineering, and computer engineering. Data collection lasted four semesters (the spring and fall semesters of 2009 and 2010).

\section{Data Collection}

Data collection lasted four semesters (the spring and fall semesters of 2009 and 2010). A total of 272 students participated in one or more of the following research methods. 
Awareness Survey To find out participants' awareness of intercultural communication, especially their awareness of culture's influence on visual, written, and oral communications, an awareness survey with open-ended questions was administered (see Appendix A for survey questions). 120 students who were enrolled in the aforementioned engineering communication class in spring and fall 2009 completed this survey. The results were then computerized for analysis (more about qualitative data analysis later).

Sensitivity Survey To find out participants' intercultural sensitivity, a sensitivity survey that included two self-report sensitivity instruments - the Inventory of Cross-Cultural Sensitivity (ICCS), first developed by Cushner in 1986 and reprinted since then [25-26] and the Intercultural Sensitivity Scale (ISS) developed by Chen and Starosta [20]—was administered. The ICCS contains 32 statements and uses a 7-item Likert Scale (Strongly Agree to Strongly Disagree). It returns a total score between 32 and 224 (higher scores represent higher intercultural sensitivity). Five sub-scales can be calculated to assess one's sensitivity in terms of Cultural Integration, Behavioral Scale, Intellectual Interaction, Attitude toward Others, and Empathy Scale. The ISS contains 24 statements that describe one's feelings toward cultural differences. It uses a 5-item Likert Scale (Strongly Agree to Strongly Disagree) and returns a total score between 24 and 120 (higher scores represent higher intercultural sensitivity). Again, five sub-scales can be calculated to assess one's sensitivity in terms of Interaction Engagement, Respect for Cultural Differences, Interaction Confidence, Interaction Enjoyment, and Interaction Attentiveness. Participants completed the survey in the engineering communication class mentioned earlier. 120 students who were enrolled in the class in spring and fall 2010 completed this survey. The results were then computerized in Excel for analysis.

Student Written Responses Participants' written responses to cultural issues can provide more contextualized data to supplement survey findings. This study used cross-cultural dialogs and critical incidents to generate responses. Commonly used in intercultural training, cross-cultural dialogs and critical incidents are brief conversations and descriptions of intercultural interactions which reveal different cultural values or communication issues [27, p. 70, p. 58]. Used in this study, they helped to reveal participants' awareness and sensitivity toward intercultural communication. Three dialogs from Storti [28] and one incident from Hall and Hall [29] were selected. They were chosen for their portrayal of professional communication problems between U.S. interactants and interactants from other cultural backgrounds (Details of each dialog and the incident are provided later in the article.). In their responses, participants commented on 1) what they thought was causing problems in the dialog or incident; and 2) what they thought could be done to resolve the problem. 
64 students participated in this part of the study in 2009 and 2010 (some of these students also participated in either the sensitivity or the awareness survey). They completed the responses in the engineering communication class mentioned earlier. Because of time constraints, each student responded to two or three of the four selections. A total of 156 responses were collected.

Student Interviews Interviews were used so participants could discuss, more in-depth, their thoughts on intercultural communication (see Appendix B for interview questions). Initially, the interviews were designed to be face-to-face group interviews. The benefits of face-to-face interviews at generating rich and personal data are well documented [30]. A group format is additionally helpful at collecting a range of different ideas [31] and encouraging young people who "need company to be emboldened to talk" [32]. It was, however, a challenge to schedule these interviews around each participant's study and work schedule. So another interview method, email interviews, was also used. Compared to face-to-face interviews, email interviews greatly reduce time constraints [33]. In addition, they allow interviewees to answer questions at their own pace and in their own comfortable environment [33-34]. Email interviews also reduce the biases caused by interviewers' nonverbal cues [34, p. 1289].

A total of 31 students participated in the interviews in 2009 and 2010 (some of these students also participated in either the sensitivity or the awareness survey). 11 of them participated in three face-to-face group interviews. These interviews were conducted at a conference room and each lasted about 30 minutes. They were audio-recorded, transcribed, and computerized for analysis. 20 students participated in email interviews.

\section{Qualitative Data Analysis}

The qualitative data collected through the awareness survey, student written responses, and interviews were analyzed using Nvivo 8. These three sets of data were separately coded. Within each data set, constant comparisons were made between data and data, data and code, and code and code to find patterns and locate emergent concepts. These concepts are described in the study findings.

\section{RESULTS}

This section reports and analyzes the findings of the study. The sub-sections Awareness Survey, Sensitivity Survey, Written Response Analysis, and Student Interviews report the respective findings of each method. The sub-section Analysis of Findings then triangulates these findings to reveal important patterns.

\section{Awareness Survey}


When asked whether intercultural communication was an important topic for them to learn, the majority of the participants $(103,86 \%)$ agreed that it was. The reasons participants believed so were mainly the influence of globalization and the changing nature of the engineering industry. Students commented that "technology is making our world smaller so in a profession such as engineering the ability to work globally is a must”; “I realize that in today's industry everything is becoming globalized. It is important to be able to understand different cultures and be able to communicate with them.” Of the other $14 \%$ of the participants, some had no opinion, some believed that it was not important for them to learn intercultural communication, and others believed that the answer depended on their career choices: If an engineer chooses to have a career outside of the U.S. or to work with international companies, then it is important, but if an engineer chooses to work in the U.S. and with domestic companies, then it is not. Figure 1 summarizes these findings.

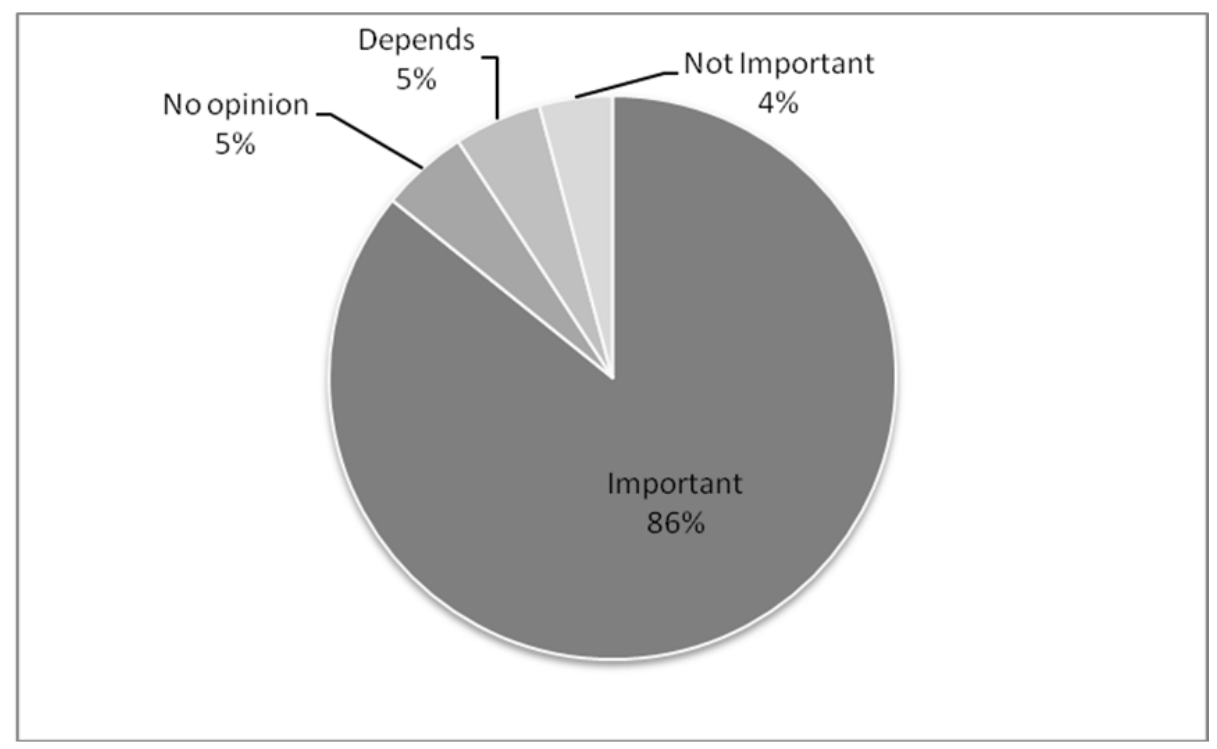

Figure 1 Is it important for engineering students to learn intercultural communication?

Awareness of Intercultural Visual Communication 19 participants (16\%) believed that technical and professional visuals were "a universal language" and perceived the same way by all people. Six participants did not respond or said they did not know. 95 participants (79\%) believed that there were cultural differences but only 22 of them were able to give any examples. In addition, many examples participants gave relate more to nonverbal communication than visual communication, namely, the use of culture-specific hand gestures such as the thumbs-up (Certainly, hand gestures can become visual communications if they are used as visual symbols.) . A few participants did mention pertinent examples. For instance, culture-specific photos may not be understood by people who lack relevant life experiences, or colors may have different connotations across cultures. Figure 2 summarizes these findings. 


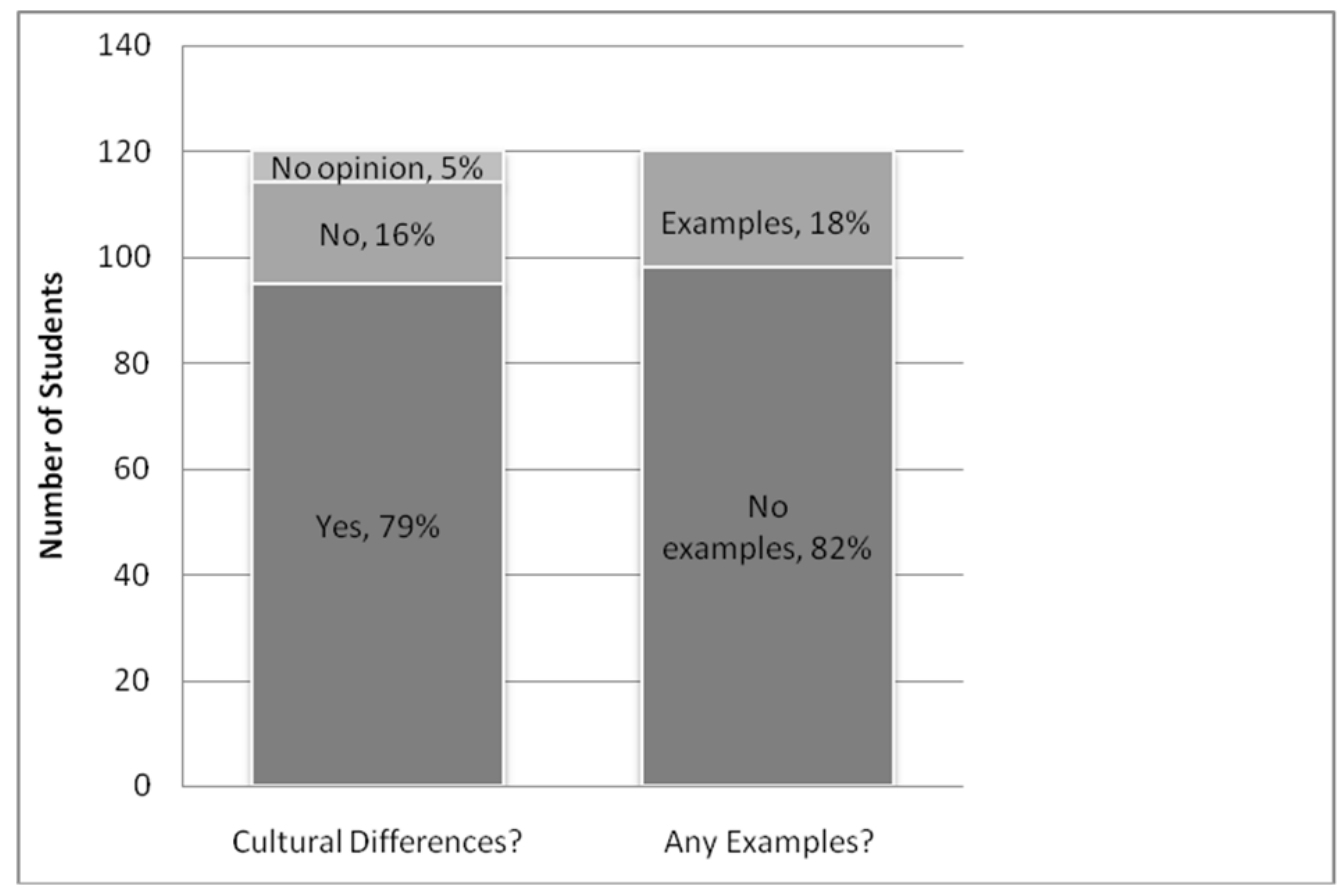

Figure 2 Participants’ awareness of cultural differences in visual communication

Awareness of Intercultural Written Communication 17 participants (14\%) did not think there were cultural differences in the ways people write professional or technical documents. These participants believed that different cultures might use different languages but they should otherwise write in same or similar ways. Or, they thought each person wrote differently and it was not culturally related. 11 participants were not sure or had no opinion. 92 participants (77\%) agreed there were differences, but only 35 of them gave examples. Some of these examples (15) are culture-related and pertinent: some cultures prefer a more concise style in writing whereas others prefer to provide more details; some cultures prefer to overview key points before giving the specifics (the deductive approach) whereas others start without an overview (the inductive approach). Other examples (20), however, explained the differences in intercultural communication in terms of non-native English writers' lack of language skills: “other cultures may use their own grammar rules even when dealing with English"; "For people who originally spoke another language, [they] think it in their language first then write in English. Therefore the writing many times has improper grammar.” Figure 3 summarizes these findings. 


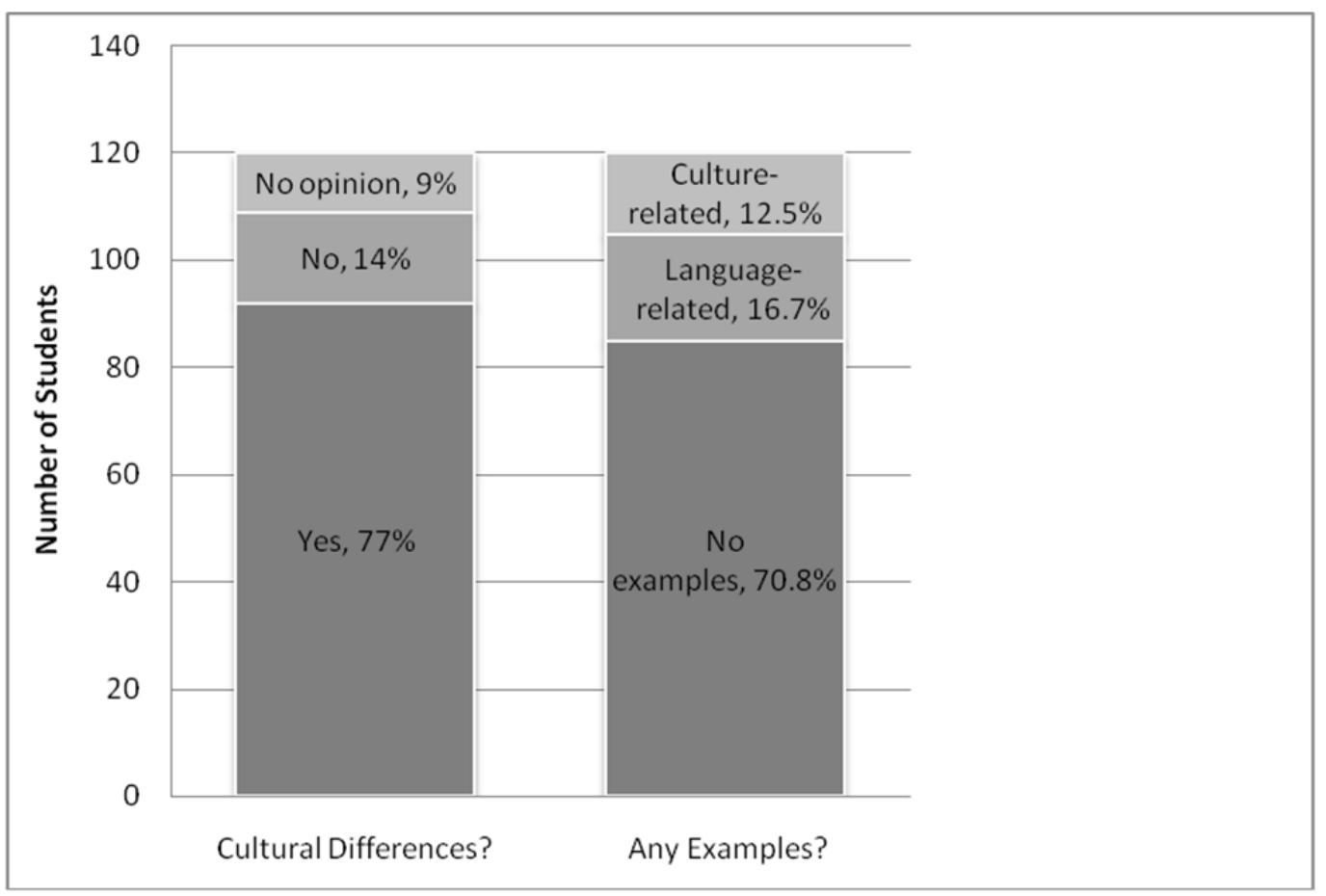

Figure 3 Participants’ awareness of cultural differences in written communication

Awareness of Intercultural Oral Communication Six participants did not think there were differences in intercultural oral communication, seven participants were not sure, and 107 participants (89\%) believed that there were differences. Compared with the earlier questions on visual and verbal communications, more participants here, 70, gave examples: different conversational spaces, greeting rituals, uses of eye contact, facial expressions, gestures, postures, conversation loudness, and levels of formality. Figure 4 summarizes these findings. 


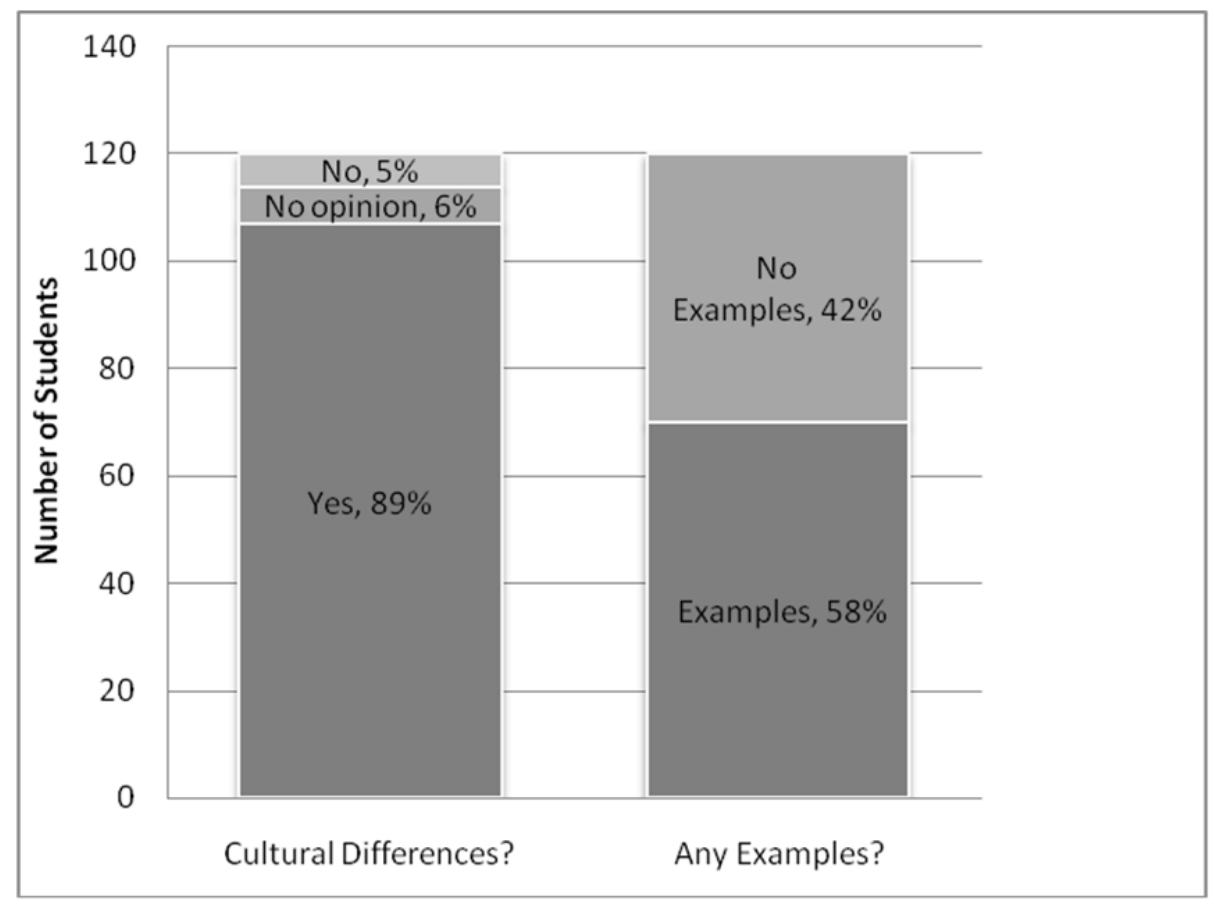

Figure 4 Participants’ awareness of cultural differences in oral communication

\section{Sensitivity Survey}

The Inventory of Cross-Cultural Sensitivity (ICCS) survey results, including sub-scale and total scores, are presented in Table 1. Table 1 also summarizes the percentages of participants whose scores are at the low, average, or high levels of intercultural sensitivity. These percentages were calculated based on the ICCS scoring guide, according to which, a total score of 32-95 suggests low sensitivity, 96-160 suggests average sensitivity, and 161-224 suggests high sensitivity (for complete details on the scoring guide, see [35]). Except for one sub-scale, Cultural Integration, the majority of the participants scored average or high on the ICCS.

Table 1 ICCS means, standard deviations, and score distributions

\begin{tabular}{lclccc}
\hline ICCS Scales & $\begin{array}{c}\text { Mean } \\
(\mathbf{n = 1 2 0 )}\end{array}$ & SD & $\begin{array}{c}\text { Low } \\
\text { Sensitivity }\end{array}$ & $\begin{array}{c}\text { Average } \\
\text { Sensitivity }\end{array}$ & $\begin{array}{c}\text { High } \\
\text { Sensitivity }\end{array}$ \\
Cultural Integration & 35 & 10 & $35.0 \%$ & $57.5 \%$ & $7.5 \%$ \\
Behavioral Response & 29 & 4 & $0.0 \%$ & $65.8 \%$ & $34.2 \%$ \\
Intellectual Integration & 28 & 6 & $1.7 \%$ & $57.5 \%$ & $40.8 \%$ \\
Attitudes Toward Others & 26 & 5 & $3.3 \%$ & $26.8 \%$ & $70.0 \%$ \\
Empathy & 27 & 4 & $0.8 \%$ & $25.8 \%$ & $73.3 \%$ \\
Total & 146 & 20 & $0.8 \%$ & $75.0 \%$ & $24.2 \%$ \\
\hline
\end{tabular}


Similar data were gathered from the Intercultural Sensitivity Scale (ISS) survey (see Table 2). The ISS does not score participants according to low, average, or high levels of sensitivity. For the ease of comparing and synthesizing the ISS and ICCS findings, a three-level scoring guide was developed based on the lowest and highest possible scores in the ISS. The total scores for ISS range between 24 (if participants choose 1 for all 24 questions) and 120 (if participants choose 5 for all 24 questions). Dividing this range into three equal portions (numbers are rounded to 1.0), a score of 24-55 suggests low sensitivity, 56-88 suggests average sensitivity, and 89-120 suggests high sensitivity. Similar to the findings with the ICCS, the majority of the participants scored high or average on the ISS.

Table 2 ISS means, standard deviations, and score distributions

\begin{tabular}{lccccc}
\hline ISS Scales & $\begin{array}{c}\text { Mean } \\
(\mathbf{n = 1 2 0})\end{array}$ & SD & $\begin{array}{c}\text { Low } \\
\text { Sensitivity }\end{array}$ & $\begin{array}{c}\text { Average } \\
\text { Sensitivity }\end{array}$ & $\begin{array}{c}\text { High } \\
\text { Sensitivity }\end{array}$ \\
Interaction Engagement & 26.6 & 3.3 & $0.8 \%$ & $32.5 \%$ & $66.7 \%$ \\
Respect for Cultural & & & & & \\
Differences & 24.6 & 3.3 & $0.8 \%$ & $23.3 \%$ & $75.8 \%$ \\
Interaction Confidence & 17.4 & 2.7 & $0.8 \%$ & $65.0 \%$ & $34.2 \%$ \\
Interaction Enjoyment & 12.1 & 1.7 & $0.8 \%$ & $28.3 \%$ & $70.8 \%$ \\
Interaction Attentiveness & 10.9 & 1.9 & $2.5 \%$ & $63.3 \%$ & $34.2 \%$ \\
Total & 91.6 & 9.7 & $0.0 \%$ & $40.0 \%$ & $60.0 \%$ \\
\hline
\end{tabular}

\section{Written Response Analysis}

In their responses to cross-cultural dialogs and critical incidents, participants first analyzed the communication problems presented to them and then suggested solutions.

Problem Analysis In general, participants made two types of problem analyses: cultural analyses and non-cultural ones. In the first category, participants explicitly attributed the communication misunderstandings or conflicts to cultural factors. In the second category, participants seemed to operate primarily from a mono-culture framework and believed that the miscommunications or conflicts happened because the parties involved in the interactions happened to have different personal styles or agendas in communication.

Following are two examples of the cultural analyses. In the first example, a participant wrote about the dialog Yamada distributors [28, p. 93], in which an American businessman Mr. Browning backed his Japanese partner Mr. Otomo into a corner trying to get the latter's personal opinion on a business proposal (Except for necessary clarifications and corrections of obvious typos, students' written responses and interview answers were quoted as they were.): 
In Mr. Browning's culture, it is alright to give your own personal/expert opinion while in Mr. Otomo’s culture, it may be more appropriate to give the opinion of the company and not what he thinks alone.

In another example, a participant wrote the following about the dialog Negotiations [28, p. 96], in which an American negotiator Janet unnecessarily lowered her asking price when her Japanese negotiator Maruoka remained silent upon hearing her offer:

Janet assumed that since Maruoka didn’t say anything right away and looked serious, that he was displeased. This is an American idea where we will try to judge what people are thinking based on how they look. Maruoka might have been from a culture where decisions were well thought through before anything was implied and Janet had a hard time relating to that.

Within the non-cultural analyses, one participant wrote the following about the dialog Yamada distributors [28, p. 93]:

It seems like Mr. Otomo has some sort of affinity toward Yamada distributors and doesn't want to change to someone else. He isn't saying anything because he doesn't want to upset Mr. Browning who wants to change.

As another example, one participant, in response to the dialog Negotiations [28, p. 96], wrote

It seems Maruoka did not know Janet was finished talking when she proposed her first price. Then while Maruoka was trying to be polite she lowered her price again. That left Maruoka wondering what was next, so of course he waited again to see what was going to happen. Her last offer was probably noted by her that she would not go lower which Maruoka accepted happily since he would have taken the first bid.

Of the 156 responses received, 62 contained cultural analyses and 87 contained non-cultural ones (the other 7 did not include relevant discussion). It is true that this cultural and non-cultural analysis categorization is not precise. Some participants, even though they did not explicitly write about culture's influence, might considered it too as they composed their answers. However, given the obvious intercultural context in the selected dialogs and incident, the large number of participants who omitted explicit discussion of culture is worth noting.

Suggested Solutions Although participants were asked to suggest solutions to solve the problems they read about in the intercultural dialogs and incident, only 95 responses contained 
suggestions and the other 61 did not, possibly because the participants were not confident or comfortable recommending solutions. The solutions that were received fall under one of the following four categories (only two responses suggested both 1 and 2):

1. The interactants should act according to U.S. norms

2. The interactants should act according to non-U.S. norms

3. The interactants should compromise and find a medium

4. The interactants should learn about cultural differences in communication

Category 1, "do things the U.S. way,” received 50 responses. For instance, participants wrote the following about the incident Meeting the German manager [29, p. 83], in which a German manager Bruning took offense when an American employee Wright wanted to become informal with him in the workplace:

Wright should try to facilitate a friendlier atmosphere. He could have...made more of an introduction to let Bruning know that he wanted to get to know him on a personal level.

Bruning should have either tried to bridge the gap with Wright from the beginning of the meeting or at least picked up on a friendly topic later.

Category 2, "do things the other way," received 16 responses. For example, one participant wrote the following about the dialog A tight schedule [28, pp. 89-90], in which an American

businessman Mr. Armstrong wanted to get down to business whereas his Middle Eastern partner Mr. Abu Bakr was interested in socializing:

Mr. Armstrong should be more personal and understand that people from different cultures don't want to simply discuss business, but also want to have friendships with their business partners. He should accept the dinner invitation and let the business discussion come about naturally instead of pushing it so hard when the other man isn't ready.

Category 3, “compromise," received 16 responses. For example, regarding the dialog A tight schedule [28, pp. 89-90], one participant wrote

While I don't feel that it is necessary for Mr. Armstrong to divulge information about his personal life if it makes him uncomfortable, I also believe that he could have been more respectful to Mr. Abu Bakr's conversation and invitation. On the opposite end, I think that Mr. Abu Bakr could have recognized that there is a real problem with the operation and Mr. Armstrong needs to fix the problem quickly. 
Last, category 4, “learn more about cultures,” received 15 responses. For instance, one participant, in response to the dialog Negotiation [28, p. 96], wrote

Janet should have done some research on how the Japanese behave during negotiations before she entered the meeting with Maruoka. She appears to have reduced the price needlessly. This situation could have been avoided if Janet would have researched about her client and came to the negotiation better prepared.

Figure 5 summarizes these findings.

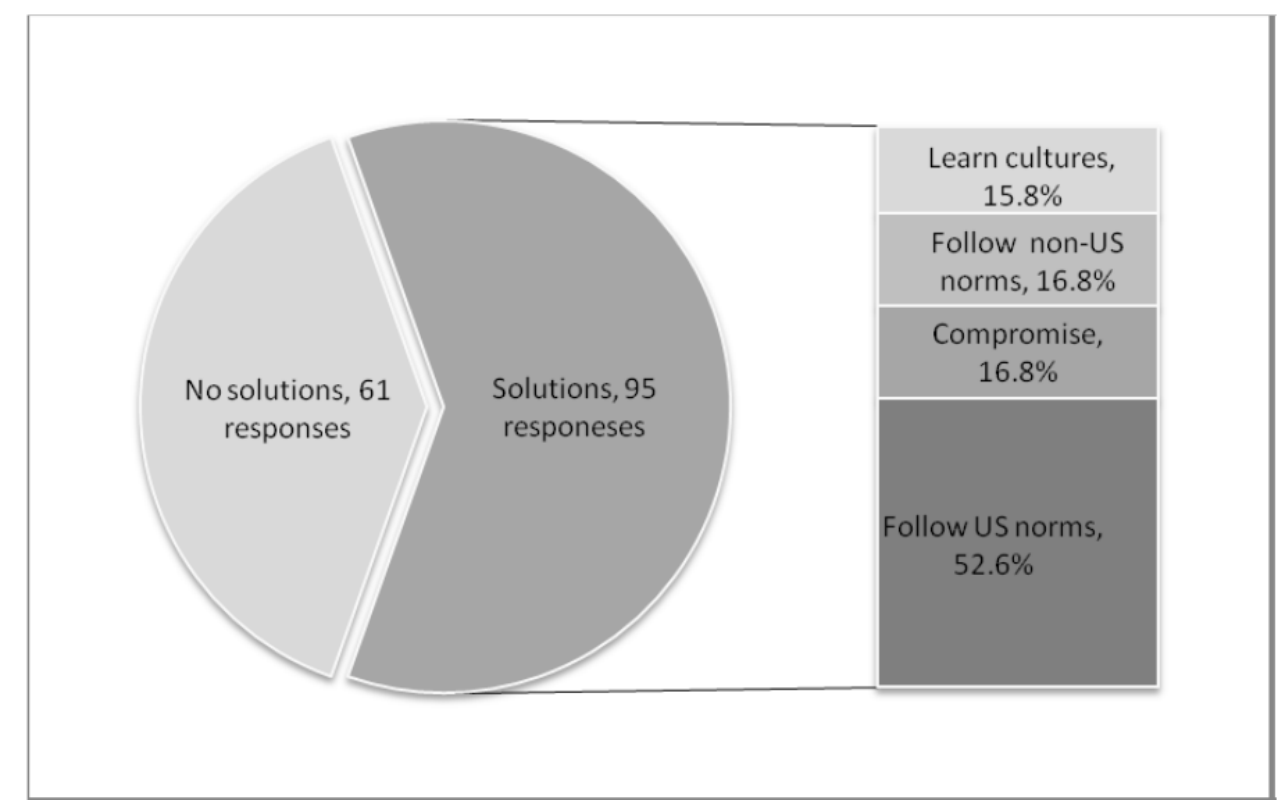

Figure 5 Solving intercultural communication problems:

Numbers and types of suggestions ${ }^{1}$

\section{Student Interviews}

The majority of the interview participants, 27 of 31, agreed that it was important for engineering students to learn intercultural communication. To the question why, they gave reasons similar to those given in the awareness survey: "The world is a much smaller place today due to technology, and different cultures meet on a daily basis in every industry" and "Engineers are expected to perform well in teams, so it seems natural that they would also be expected to work effectively in teams consisting of members with diverse cultural backgrounds.” In addition, participants drew upon personal experiences to emphasize the importance of learning intercultural communication: failed intercultural interactions they had had or previous internships with international companies.

\footnotetext{
${ }^{1}$ Percentages add up to $102 \%$ because 2 responses were counted twice under categories 1 and 2.
} 
Almost all participants admitted that they lacked intercultural communication competence. Some of them attributed this to their lack of relevant experiences:

I went to a small school whose students were almost entirely white. Aside from a few Hispanic students, a handful of African American children several years younger than me and intermittent exchange students (none in my class), there was little cultural diversity to speak of.

More participants thought that the reason was their lack of relevant intercultural communication education. As participants said in face-to-face interviews, "I don't know where to learn it. In some international engineering classes? I don't know they exist." "This is not addressed very much in my curriculum and I cannot see where it can be. All the courses are very technical.” Similar comments were made in emailed interviews:

As an engineering student, I have spent years learning and studying technical skills and haven't taken a single class regarding different cultures.... In all of my time at [the university], I haven't had an open class slot to take anything but engineering classes. From the day I first enrolled, [the university] has had a very rigorous flowchart of the classes I needed to take and when to take them. All of these classes are technical classes and each semester is pre-packed without a lot of "breathing room" for other classes.

Despite their apparent agreement on the need for intercultural communication education, half of the participants did not agree that all engineering students should be required to learn it. Their objections were similar to those given by the four participants who did not agree with the importance of intercultural communication in the first place.

Participants' first objection is that all engineers will not communicate cross-culturally in their work and only those who work in foreign countries or on international projects will:

It [intercultural communication education] would be very difficult to accomplish in a college. Most students wouldn't know where they would be working at or if they would have to deal with other cultures on a daily base.

Most of the engineers that I have gotten to know over the past two years work with people who live in the same region so they don't have major cultural differences. For these individuals cultural training would have been wasted time for the most part.

Participants' second concern is that there are many different countries and cultures in the world 
and learning about them all is impossible. They believed that intercultural training is better provided by companies and/or undertaken by individual engineers on the job:

While it is important to understand the culture that you are going to interact with, there are too many cultures and variants to learn all individually, and broad based training doesn't cover things you would actually need to know. Specific cultural issues training should be left to the individual company so it can be tailored to suit the needs and requirements of the assignment.

I think that it is the responsibility of a company to offer their employees intercultural training. This type of training could be made a mandatory part of their orientation. Each company has different needs based on the markets where they do business. They can create a training program that fits the specific need of the company.

\section{Analysis of Findings}

Vague and Passive Awareness of Intercultural Communication The majority of the students who participated in the awareness survey agreed with the importance of learning intercultural communication. Many also believed that there were cultural differences in the ways people communicate technical and professional information through visuals, texts, or face-to-face interactions. These are positive findings that suggest students' intercultural awareness.

On the other hand, very few participants were able to give concrete and appropriate examples of culture's influence on communication. In addition, of the participants who responded to the cross-cultural dialogs and critical incident, more than half were not able to (or not comfortable to) bring culture into their analyses, and only a small percentage suggested that learning about cultures and gaining cultural awareness was a solution to solving intercultural communication issues.

So it seems that, in general, the engineering students in this study had only a vague awareness of intercultural communication but lacked concrete understandings (i.e., "I would think there are cultural differences, but I don't really know what they are or what to make of them”). Their awareness also appears passive rather than active (i.e., "If you ask me, I would think it is important to learn about cultures, but I probably won’t do it myself”).

This vague and passive awareness led some participants to believe that communication problems happened in the cross-cultural dialogs and critical incident because the interactants were just being who they were-people who had different communication styles or conflicting agendas. It is true that "culture" is not monolithic and for the most part, "national cultures" can be an overgeneralized variable because each interactant will, indeed, bring to the interaction his/her own 
personal styles, individual experiences, and sub-cultural influences. But, as mentioned earlier, in the context of this study, the large number of participants who dismissed "culture" from their discussion is worth noting. As Storti reminded us, human beings internalize cultural norms by observing what happens around them and learning from people who raise them [28]. When questioned, we often cannot articulate why we behave the way we do, so when we think we are just "being ourselves” in intercultural interactions, we are really "acting according to our deepest instincts" and "[revealing] fundamental differences in what we all tend to think of as normal behavior" [28, pp. 1-2]. Students who do not see past the “personal difference” explanation minimize the influence of culture and the importance of learning intercultural communication. This minimization was also reported by Paretti, McNair, and Burgoyne [36]. The engineering students in their study tended to attribute intercultural communication barriers to the difficulties of working across disciplines, other interactants’ lack of engineering knowledge, or the challenges of long-distance communication; they showed little awareness that culture might have played a role in creating those barriers [36].

A vague and passive awareness, in some cases, led participants to form an ethnocentric view of intercultural communication. In the awareness survey, more than half of the written communication examples participants gave were not concerned with cultural differences but language differences. These participants seemed to believe that intercultural written communication will become problems when "the others" lack proficiency in the English language. No doubt, English is the language most commonly used in intercultural interactions. But this English does not mean Standard American English (SAE) but is often one of many versions of English that enable two people who have different linguistic backgrounds to understand each other. Equating intercultural English with SAE creates an unequal status for non-SAE-native speakers. It also can lead native speakers to develop language ethnocentrism and think that SAE is "the only appropriate language for social or literary expression" and “inherently the best language” [37, p. 318].

An ethnocentric view of intercultural communication is also reflected in some participants' cross-cultural dialog and critical incident written responses. By far, the most participants suggested that to solve communication problems that were presented in the dialogs and incident, interactants should communicate according to U.S. cultural norms. When students believe that "personal differences" are what cause intercultural communication problems and then go on to suggest that U.S. norms should be followed to solve these problems, we see not only a lack of intercultural awareness but an embrace of ethnocentric viewpoints. Participants who did so held biased views in favor of their ingroup members (the U.S. interactants) at the expense of the outgroup members (the non-U.S. interactants); they see the ingroup’s value standards and 
customs as universal or intrinsically true whereas the outgroup's standards and customs inferior, weak, or dismissible [38, p. 386]. Such a viewpoint will be a significant barrier for students to develop intercultural competence [38].

Average to High Intercultural Sensitivity Judging by the two sensitivity surveys, the vast majority of the participants have average to high levels of intercultural sensitivity. With the Inventory of Cross-Cultural Sensitivity (ICCS) survey, 75\% of the participants' total scores qualified for average sensitivity, with another $24.2 \%$ achieving high sensitivity. The Intercultural Sensitivity Scale survey (ISI) resulted in more positive findings: 40\% of the participants' total scores qualified for average sensitivity and $60 \%$ achieved high sensitivity. As for the two surveys' sub-scales, over $96 \%$ of the participants scored either average or high on all but one sub-scale. According to these findings, students in the study would have respect and empathy toward different cultures, would enjoy or be willing to engage in intercultural interactions, and would be confident and attentive in such interactions.

The one sub-scale in which 35\% of the participants scored low was the Cultural Integration subscale in the ICCS. This sub-scale measures participants' willingness to actually integrate with different cultures. Some statements that measure this sub-scale are "I speak only one language"; "I have never lived outside my own culture for any great length of time"; and "I think about living within another culture in the future.” It is possible that because this sub-scale measures one's active adaptation to other cultures as opposed to only being appreciative of other cultures or letting others adapt to one's own culture, students were likely to score lower.

No previous studies were found using the ICCS or ISS to measure engineering students' intercultural sensitivity, so no comparisons can be made within the discipline. One study, by Loo, was found using the ICCS on 211 management undergraduate students at a small, liberaleducation university in Western Canada [35]. Findings from Loo were similar to those obtained in this study: very few students fell in the low sensitivity category and the great majority scored average or high. Not coincidentally, in Loo, the Cultural Integration sub-scale was also an exception in which more than 15\% of the participants scored low [35]. As for the ISS, Graf and Harland administered it to 188 Masters of Business Administration students at a medium-sized Midwestern university in the U.S. [39]. Their findings are surprisingly similar to those of this study: participants' sub-scale and total score means are either identical or within a 0.4 difference.

According to these findings, the engineering students in the study had satisfactory intercultural sensitivity or were at least comparable to students in other disciplines. However, we do have to be careful in how we interpret these results. Because these surveys are self assessment in nature, 
they can lead to inflated or deflated ratings [40]. Furthermore, participants' answers to sensitivity surveys may be influenced by the social desirability bias. Students, when faced with statements such as "I would not accept the opinions of people from different cultures," can easily recognize the socially desirable answer and may consequently skew their true answers.

Because of these potential biases, participants' cross-cultural dialog and critical incident written responses are especially important at providing more contextualized and reliable data. And these responses, indeed, show less positive findings. When asked how they would solve the misunderstandings or conflicts that were presented in the dialogs and incident, $52.6 \%$ of the solutions given by the participants were that the interactants should follow U.S. communication norms. Regardless of its effectiveness, this solution, from a sensitivity perspective, suggests participants' lack of appreciation or acceptance of cultural differences. By contrast, only 33.6\% of the suggested solutions asked that interactants should compromise or follow non-U.S. communication norms.

Partial Acceptance of Intercultural Communication Education Although the majority of the interview participants agreed, in principle, to the importance of learning intercultural communication and admitted that they lacked the relevant competence, not all of them believed this topic should be included in engineering or other technical communication classes. These participants had two reasons: 1) they did not think (or did not know if) they would be involved in international work after graduation and 2) university education could not focus on the particular cultures they might need to learn for future jobs.

The first concern, many will agree, can be attributed to these participants' naivety toward the highly globalized society and industry that they are a part of, as documented at the beginning of this article. Perhaps some of their peers' interview comments are best responses to this concern:

Engineering has become so diverse and such a world wide effort for the last ten years, I find it hard to believe that engineering students are able to leave with a bachelor's degree yet still know absolutely nothing about how to handle themselves in situations outside the United States.

I sometimes think American [schools] do not teach these needed skills because they expect others to learn our way or do not look at the big picture and realize all the cultures we may be working with.

Participants' second concern, however, warrants a closer look. It is true that there are many 
cultures in the world and all cannot be learned in one or more technical communication classes. It is also true that if a particular culture is emphasized, it may not be what the students will need for their future jobs. If so, will such education be ineffective or "wasted," and is companysponsored training a better way for engineers to learn intercultural communication? To answer these questions, we need to clarify two conceptual confusions: 1) intercultural communication training equals intercultural communication education, and 2) effective cultural education/training equals culture-specific education/training.

As Gudykunst, Buzley, and Hammer wrote, intercultural training and education, despite some shared content and teaching methods, have different goals [41]. Intercultural training is often job related and aims to improve employees’ performance on their current work or work they are hired for; intercultural education, by contrast, "is not linked to specific jobs, but rather is aimed at improving individuals' overall competence” [41, pp. 64-65]. Because of its narrower goals, intercultural training faces a number of constraints. First, companies often prefer quick-fix solutions and short-term training programs (as short as a half-day session), which have dubious or limited effects [41]. In addition, intercultural training is affected by a company's political climate and corporate culture, which determines "whether or not training is conducted, who is trained, who requests the training, who conducts the training, the type of training conducted, and the resources committed to training” [41, p. 64]. For example, the more ethnocentric organizations are less likely to offer intercultural training and more likely to commit fewer resources or focus on corporate profit rather than trainees' intercultural competence development [41, p. 64]. By contrast, intercultural education, because of its focus on learner improvement, reduces or eliminates these limitations. It can reach all students rather than a select few and is less likely to be influenced by political and economic constraints.

Furthermore, company-sponsored intercultural training cannot, as students in this study imagined, focus solely on specific cultures. As Gudykunst et al. wrote, intercultural training techniques can be classified, based on their content, into culture-specific and culture-general trainings [41]. Culture-specific training is training that is specific to a culture or area; it can teach a range of information such as "factual background data, deep cultural programming, business practices, living logistics, famous people and places in the country or culture,” etc. [27, p. 72]. Culturegeneral training, by contrast, deals with topics such as raising trainees' cultural awareness and sensitivity; it allows trainees to learn about themselves, increases their understanding and/or appreciation of culture's influence on communication, and prepares trainees for interactions with any culture [41, p. 66]. Although culture-specific training is most frequently used to prepare employees for working with or living in particular cultures, this training technique does not work by itself [27]. Instead, “[a]n effective plan is to begin with culture-general principles and 
cultural-awareness learning activities, then to increase trainees' understanding of their own culture, and finally to examine the target culture" [27, p. 73]. In other words, the culture-general education students receive in technical communication classes is not "wasted" and can help build a more solid foundation for the culture-specific learning they may receive on the job. This foundation will be especially important if on-the-job training, because of those constraints mentioned earlier, sacrifices culture-general content and deals solely with culture-specific content.

Finally, the culture-general approach is deemed overall more effective than the culture-specific approach at building learners' intercultural competence. It is generally not useful "for trainees to be taught specific interpretations for specific behaviors in the host culture....Trainees will never remember all of the interpretations they are taught, and more important, there is never a one-toone correspondence between specific behaviors and specific interpretations of those behaviors" [41, p. 75]. What trainees need are frameworks (e.g., understandings of individualism and collectivism) for them to interpret unfamiliar cultural behaviors [41, p. 75]. Technical communication teachers have voiced very similar concerns. Miles, for instance, argued that our students can never remember all the numerous details on cultural differences presented in textbooks and what they need instead are frameworks and strategies to appreciate and understand other cultures [42]. Culture-general education can help students develop these frameworks and strategies, to apply "learning in creative ways to new environments," and to "[acquire] new frames of reference with which to continue inquiry" - in other words, to learn to learn cultures [43, p. 118].

\section{Conclusions, Limitations AND SUggestions for FUtURE RESEARCH}

This section summarizes the findings of the study, discusses its limitations, and suggests future research.

\section{Conclusion}

The engineering students who participated in this study exhibited vague and passive intercultural awareness and, at times, an ethnocentric view of intercultural communication. Participants' intercultural sensitivity scores are, in general, satisfactory, although these scores may be subject to self-assessment and social desirability biases. Last, although participants often agreed with the importance of intercultural communication, they had misconceptions about the effect of classroom-based education.

Given these findings, I suggest technical communication teachers use culture-general teaching methods in their classes to help engineering students raise intercultural awareness and further 
develop intercultural sensitivity. This education also prepares them for company-sponsored, culture-specific training they may receive in the future and provides them with frameworks and strategies to learn to learn new cultures. In the following, I list some of these culture-general teaching methods. This is not a comprehensive list. In particular, teaching methods that engage students in real intercultural experiences and aim to develop students' behavioral skills are not included. For more possibilities, see [5, 44-47]. Considering the limited time and effort service class teachers can devote to intercultural issues, I tried to offer methods that are, relatively speaking, easy to implement.

Lectures/Discussions Supported by Cultural Artifacts Lectures and discussions are common methods to teach intercultural awareness and cultural frameworks [41] and they are already commonly used in technical communication classes [48]. What I suggest is that teachers use more cultural artifacts to support these lectures and discussions. The particular cultures featured in these artifacts are not important in culture-general education. Yu (2011) suggested a number of print artifacts, some of which are geared specifically toward engineering students, for instance, visuals used in product manuals [5]. In addition, films and videos, with their audio and visual components, can bring experience, ideas, and emotions together and evoke powerful feelings in participants [27, p. 53]. Flower and Blohm [27] and Tippens [49] suggested a number of film and video titles, but a great many possibilities exist. Examples include The Joy Luck Club (1993), which portrays Chinese-U.S. cultural clashes; Lost in Translation (2003), which contrasts U.S. and Japanese cultures; House of Sand and Fog (2003), which describes Iranian-U.S. interactions; and many more.

After reading and watching these artifacts, students can be asked to reflect, either through writing or group/class discussion, what knowledge they gained about "other" cultures, what they learned more about U.S. cultures, and what are the bearings of these cultural factors on communication. Teachers can also introduce the class to relevant cultural frameworks and theories. The point of these exercises is not to familiarize students with a particular culture (although that does happen and is a positive outcome), but to help students see culture's influence on communication, to exemplify relevant cultural factors, and to evoke positive feelings from students toward cultural differences.

Cross-Cultural Dialogs and Critical Incidents As mentioned earlier, cross-cultural dialogs and critical incidents are brief conversations or descriptions that portray intercultural communication misunderstandings or conflicts. Through characters, dialogs, and plots, they can help students experience a large spectrum of cultural values, norms, and viewpoints. Storti, for instance, included conversations between U.S. interactants and interactants from British, German, French, 
Arab, Chinese, Japanese, Hispanic, and other cultural backgrounds [28, 50]. A well-known success, Cushner and Brislin's collection includes incidents from multiple countries and explores themes such as time and space, work and family, and groups and individuals [51]. Many of these dialogs and incidents happen in workplace settings or involve professional topics and will be relatable to engineering students.

Teachers can ask students to read these dialogs and incidents and then discuss, either through short written responses, in small groups, or as a class, what was going on in the dialog/incident, what problem, if any, transpired, why, and what can be done about it. Although cross-cultural dialogs and critical incidents may not provide "the deeper, systematic investigation of a specific context as with case studies” [27, p. 58], they are easier to implement, more suitable for service classes, and can illustrate culture's influence on communication.

Cross-Cultural Analysis Cross-cultural analysis is an experiential exercise in which students "respond to a series of contrasting values or cultural orientations from the point of view of their own culture and that of [other] cultures" and then discuss their responses [27, p. 69]. Limaye used this method to teach intercultural business communication, asking students to respond to statements such as "Decision by consensus should be the preferred management style in businesses organizations" and "The United States has no moral right to lecture other countries about human rights because it has violated human rights itself a number of times in its history" [52, p. 37]. As Flower and Blohm wrote, for naïve students, such an exercise "may be the first time they realize that what they had assumed was universal is actually culturally determined. The exercise encourages [students] to develop cultural self-awareness and an awareness of different worldviews” [27, p. 69].

Used with engineering students, the cross-cultural statements can be written to relate to the engineering industry, for instance, "Outsourcing engineering jobs to other countries destroys American working people and their families" or "The United States should not blame thirdworld countries for green gas emissions because it imports many products manufactured in those countries." Students can respond to these statements in writing or discuss them in small groups or as a class.

Culture-General Simulations Simulations are "experiential exercises designed to simulate general interaction between members of different cultures" [41, p. 70]. Typically, students play the members of multiple cultures (often hypothetical ones to prevent stereotyping) who have different communication norms and try to interact with each other. Popular simulations include Bafá Bafá, Ecotonos, and Barnga, which are commercially available [53-55]. Teachers can also 
design their own simulations to better target a given student population. Jameson, in teaching international business communication, designed three hypothetical cultures whose members must collaborate on a joint business venture [56]. For engineering students, technical communication teachers may use generic simulations or, if time permits, design particular simulations with engineering communication contexts and goals.

Each simulation works differently according to its own rules and often with specific tools, but most of them are flexible: they can be used with all kinds of students, can accommodate different numbers of students and different time limits, and can be run at various levels of complexity. Generally speaking, students are first grouped into different “communities," each with its own implicit and explicit rules and norms. After learning these rules and norms, students will venture out to interact with other communities to realize certain goals. The rules that are followed by different communities are purposefully designed to be different or contradictory, which will frustrate students as they try to communicate with each other. When students are sufficiently frustrated, teachers will conduct debriefing, which is the most important part of a simulation that guides students to develop intercultural awareness and sensitivity. During debriefing, students are guided to "reflect on their experience, relate it to the real world, discover useful insights, and share them with each other" [55, p. 16]. Teachers can use various prompt questions to facilitate this discussion, and some questions Thiagarajan suggested are How do you feel? What happened? What did you learn? How does this relate to the real world? What if? and What Next? [55, pp. 17-22].

\section{Limitations}

Data from this study are collected from engineering students in one Midwestern public university. These participants, as most students in the university, are in-state students and of a certain demographical background, so findings from this study may reflect regional tendencies and cannot be generalized to all U.S. engineering students. Even within the same Midwestern region, findings from this study may not be generalizable because engineering students who attend different institutions may have different curricular experiences that impact their intercultural competence. This study was also limited in its scope. It assumed that intercultural awareness and sensitivity are the foundation of students' performance on the third aspect of intercultural competence, skills, and did not directly examine students' intercultural skills.

\section{Suggestions for Future Research}

Similar studies can be conducted with engineering students in various programs and regions to address the limitations of this study; researchers may also directly examine students' intercultural skills to enrich their findings. Additional culture-general teaching methods may be examined, 
and in particular, classroom studies that implement these methods in the engineering communication service class are needed. Engineering faculty and program administrators should actively encourage as well as participate in these studies. With these works, we can hope to better understand engineering students' learning needs and design the best teaching methods for their global education.

\section{APPendix A AWARENESS SURVeY}

1. What is your major and year in school?

2. Do you believe it important for you to learn intercultural communication? Why or why not?

3. Do you think different cultures read or interpret technical and professional visuals (photos, illustrations, graphs, etc.) differently? If so, can you give any examples?

4. Do you think different cultures use different strategies or styles when writing technical or professional documents such as letters, proposals, and reports in English? If so, can you give any examples?

5. Do you think different cultures have different preferences for face-to-face communications such as presentations and meetings? If so, can you give any examples?

\section{APPENDIX B INTERVIEW QUESTIONS}

1. What is your major and year in school?

2. Do you believe it important for engineering students to learn intercultural communication? Why or why not?

3. What is your level of intercultural communication competence? How did you gain it or why do you think you lack it?

4. Do you think intercultural communication should be taught in engineering communication classes or other technical communication classes for engineering students? Why or why not?

\section{REFERENCES}

[1] A. Mazumder, Making of a Global Engineer: Philosophy and Practice. Bloomington, IN: AuthorHouse, 2008.

[2] P. Camuti. (2006). Engineering the future: Staying competitive in the global economy, Online Journal for Global Engineering Education. [Online]. Available: http://digitalcommons.uri.edu/cgi/viewcontent.cgi?article=1000\&context=ojgee 
[3] H. E. Nystrom, "Managing cultural differences for engineers," 27th Frontiers in Education Conf., Pittsburgh, Pennsylvania, 1997, pp. 812-814.

[4] C. Del Vitto. (2008). Cross-cultural "soft skills" and the global engineer: Corporate best practices and trainer methodologies. Online Journal for Global Engineering Education. [Online]. Available: http://digitalcommons.uri.edu/cgi/viewcontent.cgi?article=1008\&context=ojgee

[5] H. Yu, "Integrating intercultural communication into an engineering communication service class,” IEEE Transactions on Professional Communication, vol. 54, no. 1, pp. 8396, 2011.

[6] L. Beamer, and I. Varner, Intercultural Communication in the Global Workplace. NY: McGraw-Hill, 2008.

[7] N. Hoft, International Technical Communication: How to Export Information about High Technology. New York: John Wiley \& Sons, 1995.

[8] C. Lovitt and D. Goswami, Exploring the Rhetoric of International Professional Communication: An Agenda for Teachers and Researchers. Amityville, NY: Baywood Publishing, 1999.

[9] T. Weiss, “' 'The Gods Must Be Crazy’: The challenge of the intercultural,” Journal of Business and Technical Communication, vol. 7, no. 2, pp. 196-217, 1993.

[10] C. Demetry, "Work in progress - Development of intercultural sensitivity from study abroad programs,” 37th Frontiers in Education Conf., Milwaukee, WI, 2007, pp. T2A-4 T2A-5.

[11] J. Widmann and L. Vanasupa , "Work in progress - Attaining and measuring global competency for engineering graduates," 38th Frontiers in Education Conf., Saratoga Springs, NY, 2008, pp. F1E-11- F1E-13.

[12] J. Thompson and B. Jesiek, "Assessing the intercultural competence among sophomore mechanical engineering students: Baseline data and analysis,” Proc. 2010 ASEE Annual Conf. and Exposition, Louisville, KY, June 20-23, 2010.

[13] Y. Shen, B. K. Jesiek, and Y. Chang, "Cultural orientation and global competency: A comparative assessment of engineering students," Proc. 2011 ASEE Annual Conf. and Exposition, Vancouver, B.C., Canada, June 26-29, 2011.

[14] M. R. Hammer, "A measure of intercultural sensitivity: The Intercultural Development Inventory,” in Intercultural Sourcebook, vol. 2, S. M. Fowler and M. G. Fowler, Eds. Yarmouth, ME: Intercultural Press, 1999, pp. 61-72.

[15] A. R. Bielefeldt and K. A. High , "Work in progress - assessing the cultural competency of engineering students," 37th Frontiers in Education Conf. Milwaukee, WI, 2007, pp. S2G-5- S2G-6. 
[16] J. R. Lohmann, J. Gordon, K. E. Harwell, S. W. McLaughlin, and S. E. Paraska. (2008). Annual Impact Report of the Quality Enhancement Plan on Student Learning: Strengthening the Global Competence and Research Experiences of Undergraduate Students. [Online]. Available: http://www.provost.gatech.edu/assets/200708QEPAnnualImpactReport.pdf

[17] G. L. Downey, et al., "The globally competent engineer: Working effectively with people who define problems differently,” Journal of Engineering Education, vol. 95, no. 2, pp. 107-122, 2006.

[18] S. Tomlinson-Clarke, "Assessing outcomes in a multicultural training course: A qualitative study,” Counseling Psychology Quarterly, vol. 12, no. 2, pp. 221-231, 2000.

[19] J. M. Bennett and M. J. Bennett, "Developing intercultural sensitivity: An integrative approach to global and domestic diversity," In Handbook of Intercultural Training, D. Landis, J. Bennet, and M. J. Bennett, Eds., 3rd ed. Thousand Oaks, CA: Sage, 2004, pp. 147-165.

[20] G. M. Chen and W. J. Starosta. (2000, November). The development and validation of the intercultural sensitivity scale. Paper presented at the annual meeting of National Communication Association. Seattle, Washington. [Online]. Available: http://eric.edu.gov (ED447525)

[21] R. W. Brislin and T. Yoshida, Intercultural Communication Training: An Introduction. Thousand Oaks, CA: Sage, 1994.

[22] G. M. Chen and W. J. Starosta, "A review of the concept of intercultural sensitivity," Human Communication, vol. 1, no. 1, pp. 1-16, 1997.

[23] G. M. Chen and W. J. Starosta, "A review of the concept of intercultural awareness," Human Communication, vol. 2, no. 1, pp. 27-54, 1998.

[24] D. K. Deardorff, "Identification and assessment of intercultural competence as a student outcome of internationalization,” Journal of Studies in International Education, vol. 10, no. 3, pp. 241-266, 2006.

[25] K. Cushner, The Inventory of Cross-Cultural Sensitivity. School of Education, Kent State University, 1986.

[26] K. Cushner, Human Diversity in Action: Developing Multicultural Competencies for the Classroom, 3rd ed. NY: McGraw-Hill, 2006.

[27] S. M. Fowler and J. M. Bohm, “An analysis of methods for intercultural training,” In Handbook of Intercultural Training, D. Landis, J. Bennet, and M. J. Bennett, Eds., 3rd ed. Thousand Oaks, CA: Sage, 2004, pp. 37-84.

[28] C. Storti, Cross-Cultural Dialogues: 74 Brief Encounters with Cultural Difference. Yarmouth, ME: Intercultural Press, 1994. 
[29] E. T. Hall and M. R. Hall, Understanding Cultural Differences: Germans, French and Americans. Boston, MA: Intercultural Press, 1990.

[30] S. Merriam, Qualitative Research and Case Study Applications in Education. San Francisco, California: Jossey-Bass, 1998.

[31] R. K., Merton, M. Fiske, and P. L. Kendall, The Focused Interview: A Manual of Problems and Procedures. NY: The Free Press, 1990.

[32] C. Glesne and A. Peshkin, Becoming Qualitative Researchers. New York: Longman, 1991.

[33] R. Opdenakker. (2006). Advantages and disadvantages of four interview techniques in qualitative research. Forum: Qualitative Social Research. [Online]. Available: http://www.qualitative-research.net/index.php/fqs/article/view/175

[34] L. I. Meho, "E-mail interviewing in qualitative research: A methodological discussion," Journal of the American Society for Information Science and Technology, vol. 57, no. 10, pp. 1284-1295, 2006.

[35] R. Loo, “A structured exercise for stimulating cross-cultural sensitivity,” Career Development International, vol. 4, no. 6, pp. 321-324, 1999.

[36] M. Paretti, L. McNair, and C. Burgoyne, "Pedagogies for developing cross-cultural communication competencies in an era of virtual collaboration," IEEE International Professional Communication Conf. Proc., Saratoga Springs, NY, Oct. 2006, pp. 5-10.

[37] R. L. Garcia, "Deep drinking: Rx for teaching English without ethnocentrism,” Clearing House, vol. 63, no. 7, pp. 318-321, 1990.

[38] J. W. Neuliep and J. C. McCroskey, "The development of a U.S. and generalized ethnocentrism scale," Communication Research Reports, vol. 14, no. 4, pp. 385-398, 1997.

[39] A. Graf, and L. K. Harland, "Expatriate selection: Evaluating the discriminant, convergent, and predictive validity of five measures of interpersonal and intercultural competence,” Journal of Leadership and Organizational studies, vol. 11, no. 2, pp. 46-62, 2005.

[40] D. Boud and N. Falchikov, "Quantitative studies of student self-assessment in higher education: A critical analysis of findings,” Higher Education, vol. 18, no. 5, pp. 529-549, 1989.

[41] W. Gudykunst, R. Guzley, and M. Hammer, “Designing intercultural training,” In Handbook of Intercultural Training, R. Bhagat and D. Landis, Eds., $2^{\text {nd }}$ ed. 1995, pp. 6180.

[42] L. Miles, "Globalizing professional writing curricula: Positioning students and repositioning textbooks,” Technical Communication Quarterly, vol. 6, no. 2, pp. 179-200, 1997. 
[43] J. M. Bennett, "Modes of cross-cultural training: Conceptualizing cross-cultural training as education,” International Journal of Intercultural Relations, vol. 10, pp. 117-134, 1986.

[44] L. Beamer, "Finding a way to teach cultural dimensions," Business Communication Quarterly, vol. 63, no. 3, pp. 111-118, 2000.

[45] J. Corbett, "From dialog to praxis: Crossing cultural borders in the business and technical communication classroom,” Technical Communication Quarterly, vol. 5, no. 4, pp. 411424, 1996.

[46] D. DeVoss, J. Jasken, and D. Hayden, "Teaching intracultural and intercultural communication: A critique and suggested method,” Journal of Business and Technical Communication, vol. 16, no. 1, pp. 69-94, 2002.

[47] D. Bosley, Global Contexts: Case studies in International Technical Communication. Boston: Allyn \& Bacon, 2001.

[48] N. Matveeva, "Teaching intercultural communication in a basic technical writing course: A survey of our current practices and methods," Journal of Technical Writing and Communication, vol. 38, no. 4, pp. 387-410, 2008.

[49] D. Tippens, "Interculturalizing the technical or business communications course," Journal of Technical Writing and Communication, vol. 23, no. 4, pp. 389-412, 1993.

[50] C. Storti, Old World/New World: Bridging Cultural Differences: Britain, France, Germany and the U.S. Yarmouth, ME: Intercultural Press, 2001.

[51] K. Cushner, and R. W. Brislin, Intercultural Interactions: A Practical Guide, 2nd ed. Thousand Oaks, CA: Sage, 1996.

[52] M. R. Limaye, "Perception is the thing: Presenting variant worldviews in the international business communication classroom,” Business Communication Quarterly, vol. 63, no. 3, pp. 24-38, 2000.

[53] Bafá Bafá. Del Mar, CA: Simulation Training Systems, 2008.

[54] Ecotonos: A multicultural Problem Solving Simulation. (2008). Boston: Nicholas Brealey Publishing.

[55] S. Thiagarajan, Barnga: A Simulation Game on Cultural Clashes. Boston: Nicholas Brealey Publishing, 2006.

[56] D. A. Jameson, "Using a simulation to teach intercultural communication in business communication courses," Bulletin of the Association for Business Communication, vol. 56, no. 1, pp. 3-11, 1993. 